\title{
Postponement in a Cold Food Chain: Production in Brazil
}

\author{
Vinícius Zomkowski Salvi ${ }^{1} \&$ Sergio Fernando Mayerle ${ }^{1}$ \\ ${ }^{1}$ Santa Catarina Federal University, Brazil \\ Correspondence: Vinícius Zomkowski Salvi, Santa Catarina Federal University, Brazil. E-mail: \\ vinicius.salvi@gmail.com
}

Received: June 24, 2014

Accepted: July 30, 2014

Online Published: August 25, 2014

doi:10.5539/ibr.v7n9p130

URL: http://dx.doi.org/10.5539/ibr.v7n9p130

\begin{abstract}
This article uses a literature review about postponement, decoupling point and cold chain to offer alternatives for Brazilian distribution of refrigerated chicken. It was possible to conclude that a decoupling point between first and further industrialization can be a viable option for selling and distributing refrigerated chicken that has from seven to maximum of thirty days of shelf life.
\end{abstract}

Keywords: agility, lean production, case studies

\section{Introduction}

Pull postponement is the process of having the decoupling point earlier in the production process (Gower ed., 1998). It can also be known as a rise in the number of unfinished or generic products succeeded by their fast transformation into finished products when the real demand is known (Christopher, 2005). The Brazilian market of beverage and food still concentrate in push process with a lack of integration between industry and retailers. It gets harder to give examples of pull postponement in those industries.

Postponement and other leagile techniques can provide a large number of benefits to that market. It can give availability in shelf life conditions, reduce costs, add value and increase margins. Some products such as dairy food and milk use real sales information for producing the next batch, minimizing waste. The whole market, however, is a push system and it is dominated by frozen food in ready meals, hamburgers, pies and ready snack categories, all of them $100 \%$ sold frozen. In chicken, pork and pizza there are more offerings in chilled chains rather than frozen (Nielsen, 2012) (Kantar, 2010). However, the biggest companies do not offer these last three products chilled, only frozen. Local and regional producers dominate those chilled markets with a discussible quality.

For sales all around the country, companies have developed a sophisticated supply chain that embraces almost the whole country with distribution centers, hubs, thousands and thousands of trucks, a huge sales force, in less quantity ships and almost no use of airplanes, which are very expensive, especially in a market with a low gross sales margin. Some products spend more time traveling than in a DC where it waits to be sold. Those products leave industry, are stored in a hub and a long time after completing a cargo, they are sent to distribution centers and only there are they available to be sold by sales force. This system worked well to provide frozen food and offer to Brazilian household a trustful high quality food. However, following Europe and The United States of America, Brazilian consumers are looking for chilled food that has a rather short shelf life, but which, for the consumer represents fresh food.

This report has made a bibliographic investigation about leagile and a case study of Brazilian food companies supply chains. It has proposed a way for the distribution of chilled food to become viable in South and Southeast Brazil. Leagile is the method of supply chain that we chose and it provides a theory base. The next part defines leagile, postponement, push demand systems and decoupling point. Then it brings the nowadays food supply chain used by big companies in Brazil. Finally it demonstrates the proposed new supply chain.

\section{Postponement for Mass Customization}

"Mass customization allows companies to penetrate new markets and capture customers whose special or personal needs could not be met by standard products", (Gattorna ed, 1998, p. 78). It forces companies to develop tools to provide specific differentiated products and "postponement is a practical manner for realizing mass customization" (Hoek \& Hoek, p. 20). Postponement allows companies to deal with a dynamic 
environment caused by increasing pressure on costs such as logistics, inventory and manufacturing. It can also increase product availability and significantly lower inventory investments (Gattorna ed., 1998).

"Postponement refers to the process by which the commitment of a product to its final form or location is delayed for as long as possible", (Christopher, 2005, pp. 134). It means that a final product differentiation is delayed as far as possible until close to when demand for the product is known (Graman, 2010). For the delayed differentiation, as postponement is also known, "has been conceived as an effective way in both academia and industry to deal with the conflicts between product diversity and inventory cost savings" (Tang, 2011, p. 481).

Postponement includes "not only relocation of inventories but also the repositioning of several activities like labeling, packaging, assembly and manufacturing" (Brun \& Zornini, 2009, p. 206). It is also a way to deal with product proliferation without generating large operating costs (Wong et al., 2011). "This is done by properly designing the product structure and the manufacturing and supply chain process, so as to delay the point in which the final customization of the product is to be configured" (Wong et al., 2011, p. 355). Those authors did a research considering the differentiation point of postponement a make to order point and not make to stock, the same definition we propose in our case study.

Reimann (2012) did a simulation of postponement related to accurate response. The possibility of using reactive capacity, which is one of the main determinants for accurate response, was used as a base to define the benefits of delayed product differentiation. In his conclusions he defended that it was interesting to use reactivity capacity for allowing being manufactured speculatively the general components in such a way that valuable reactive capacity can be used effectively to customize the final product according to the customer demand. His sensitive analysis suggested that the cost of general component and the level of reactive capacity have the strongest impact on the profitability of postponement, while the "level of demand uncertainty and the ratio between the cost of the general component and the cost of customizing this component seem to be of smaller importance" (Reimann 2012, p. 628).

There are at least three different postponements: logistics postponement, form postponement and pull postponement (Gattorna ed., 1998); or time postponement, place postponement and form postponement (Brun \& Zornini, 2009). Pull postponement is a process of delaying the final transformation of a product as far as possible. Logistics postponement means to transfer final transformation to another place along the distribution chain. Finally, Form Postponement is the process of altering the design of product and process for postponing and becoming a flexible production. According to Wong et al (2011), some authors consider Logistics Postponement as a combination of both Time Postponement and Place Postponement. In this way, logistics postponement is combination of the first two (time and place).

Postponed manufacturing combines these three types; final processing and manufacturing activities are postponed until customer orders have been received (time postponement) and are performed from central operations in the international supply chain (place postponement), to include customer- and country-specific characteristics in the finished product (form postponement), frequently followed by direct delivery to retailers or customers. (Hoek, 1997, pp. 63-64).

There is an optimization of the use of postponement, and that is because at least two issues can block the viability of the delay differentiation of a product: first, the marginal benefit diminishes when more products are postponed; and second, the costs linked to postponement indicate that in some amounts their value overtake costs of a normal production with no postponement (Graman, 2010, p. 34). So, our case study considers the option of partial postponement.

$\mathrm{Xu}$ (2011, p. 75), studying whether it is better to produce $100 \%$ postponed or have a mix with some products being produced simultaneously, not postponing, proved that using hybrid postponement strategies (part postponed and part no postponed) for both products simultaneously "is not optimal if the benefit of postponing one product is higher than postponing the other product".

Finally, Yang, Burns and Backhouse (2004) gave us the reasons why postponement has become important in this current market: unpredictable environment, short product life cycles, high competitive markets, and it is "also favorable due to uncertainty about customer requirements and technical evolution during the development process" (p. 472).

\section{Decoupling Point}

The CODP - customer order decoupling point_represents the moment where the product is differentiated for meeting final demand. It is a point in the value chain for a product where it is linked to a specific customer demand Olhager (2010). This point divides what is forecast-driven (upstream of CODP) from what is customer 
order-driven (downstream CODP). As we can see in the following graph, make-to-order, make-to-stock, assemble-to-order and engineer-to-order have a decoupling point in different moments of a line of production Olhager (2010)

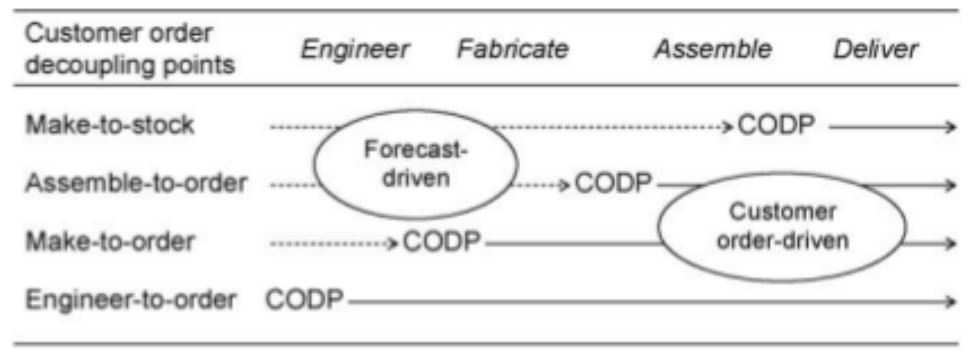

Figure 1. CODP (customer order decoupling point)

Source: Olhager (2010).

Romme (apud Donk 2001, pp. 298) defines decoupling point as "the point that indicates how deeply the customer order penetrates into the goods flow". Sun (2008) affirms that DP is the boundary between MTO and MTS. For Donk (2001) Decoupling point is important for at least three points: it separates demand-driven to forecast-driven, it is the main stock for where delivery to customers is made and upstream activities can be optimized once they are separated from irregular demand effect.

Donk cited different structures for CODP than those used by Olhager (2010). He considered 5 types: make to local stock, make to stock, make to order, assemble to order and purchase and make to order. The table below was the base for classifying into those five options.

Table 1. Determinants of the decoupling point

\begin{tabular}{ll}
\hline Product and market characteristics & Process and stock characteristics \\
\hline Required delivery reliability & Lead times and costs of steps in the (primary) process \\
Required delivery time & Controllability of manufacturing and procurement \\
Predictability of demand & Costs of stock-holding and value added between stock points \\
Specificity of demand & Risk of obsolescence \\
\hline
\end{tabular}

Source: Donk (2001).

Researchers on Leagility try to create an appropriate Decoupling Point allowing postponement processes (Herer et al., 2002). For the same authors the postponement (pp. 221) needs "modifications in product and process designs as well as in organizational relationships". So they studied transshipment as an option for Leagility, replacing what they defined as postponement and decoupling point as being not practical. However, we do not agree that one (transshipment) can replace the other (postponement).

The optimal placement of the CODP, (following Hedenstierna \& Ng, 2010), depends on the signal of the demand. Their findings indicate that the position of the CODP downstream allows for short-term fluctuations in demand to be immersed by the order, leading to a more stabilized production rate. The decoupling point as far as possible in the downstream makes "possible to filter out high-frequency variations in demand". By doing this, the system will reduce the pressure on the physical supply chain, "reducing the need for a safety stock or overtime". (Hendenstierna \& Ng, 2010, p. 6). Bellow there is a figure showing what the CODP is. 


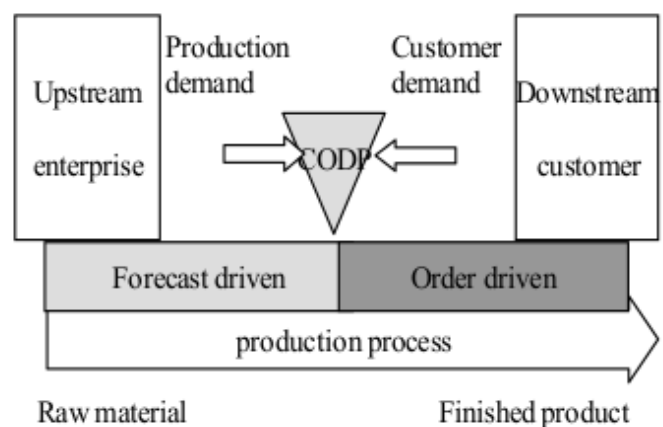

Figure 2. Decoupling point

Source: Xu (2007).

\section{The Chilled Chain}

A chilled chain is a bunch of processes - production, chilling, warehousing, picking, transportation, final destination on displays of groceries and others - of particular products that must be kept during the entering process in a rigorous controlled temperature. During the primary chilling, meat temperatures, for example, must be reduced below $7^{\circ} \mathrm{C}$. There, the meat will be submitted to a temperature of $-15^{\circ} \mathrm{C}$ to $-70^{\circ} \mathrm{C}$ during the first stage of the process until it achieves $7^{\circ} \mathrm{C}$. To keep the shelf life of the product, for example, transportation must be between $-1^{\circ} \mathrm{C}$ to $0.5^{\circ} \mathrm{C}$. James (1996).

Chilled chain is worse to transport than frozen foods because temperatures below $-18^{\circ} \mathrm{C}$ have no serious quality or safety issues in cases of subtle losses of temperatures. Only products above $-12^{\circ} \mathrm{C}$ of temperature have been associated with an increase in bacterial counts and losses of quality, (Estrada-Flores apud Da-Wen Sun ed. 2006). Chilled cargo requires more energy than frozen cargos and needs to be faster because time spent is equal to progressive loss in quality. A frozen food allows companies to have a longer time frame and be beneficiated by a better use of cost and energy. (Estrada-Flores apud Da-Wen Sun ed. (2006).

Rodriguez, Amorrortu and lvarez (2011, p. 73) affirm that "controlling the cold chain is a fundamental aspect for all companies in the food and health industries". Pre-cooked products, those through wich raw materials undergo a huge rate of manipulation and which in many cases the shelf life is extended, need a developed and rigorous cold chain. Following these authors there are lots of reasons why temperature operations diverge from what was planned: "the doors of the refrigeration unit remaining open for an excessive period of time, equipment fails to cool correctly due excessive amount of ice, $[\ldots]$ failure of the temperature control's thermocouples [...]".

Zanoni and Zanavella (2012, pp.735) made a research about optimization of energy use for frozen and chilling potatoes. They concluded something a little bit different than Strada-Flores. They wrote down that higher storage temperature "may be attractive in terms of setup and preservation costs, but, because of accelerated degradation of the product quality, the total cost increases". That conclusion was based on the fact that consumers in those markets are keen to pay more for fresher products. It is a premise that the company studied by us had also taken for introducing refrigerated products into its portfolio.

Raab, Petersen and Kreyenschmidt (2010) corroborate with Rodrigues Amorrortu and lvarez (2011) about the importance of controlling temperature and citing other causes for losing it. They affirm that "it is well known that temperature is the most important influencing factor on meat quality and safety" (pp. 271). They also show that incorrect handling, improper storage and transportation conditions correlated with temperature "leads to a reduction in shelf life" (p. 272). They also commented that studies in temperature indicators have been discussed exhaustively in recent years but implementation in the meat industry has only recently begun. Our researched company has technologies for controlling temperature such as sensor of cold transmitted by GPRS technology to a monitoring central, but it still needs to be improved for implementing refrigerated distribution.

It is not uncommon to have trucks loading without pre-cooler, a process through wich the cabin must pass to achieve the necessary temperature for a safe loading. So, the first products that are stored inside the compartment can be submitted to high variations of temperature. It is also not uncommon to have cars transporting frozen food with the Thermo King broken. even On holidays' it is also possible to have cars being loaded without separation of frozen and refrigerated products; those cars will spend all holiday waiting to be loaded for next day to be delivered to clients. Those points are here registered because all big companies in Brazil are not working 
properly in safety distribution conditions. It is elementary to fix this to be able to serve customers with safely refrigerated products, which are even worse than frozen foods in exigencies of keeping temperature.

Another important point is that in Brazil, unlike England and The USA, for instance, the frozen food of chicken is the main option at sales points. In England, refrigerated chicken represents more than $80 \%$ of sales. Maybe because of the difficulties of transport the frozen chicken that we related above and because some areas of Brazil, such as the Northeast and North, are far away from production areas, in Brazil the market is different and absolutely dominated by frozen chicken. It is important to say that refrigerated food has proved to be healthier than the frozen one.

\section{The Case Study}

Brazil is the third biggest chicken producer in the world, following the USA and China and it is the main exporter, following by the USA. South Brazil and Center-West are the major producer regions. Both regions are also major producers of soya and corn, components of the chicken meal. However, the Brazilian main market is São Paulo, Rio de Janeiro and Minas Gerais, three states localized in the Southeast Brazil and the most profitable regionS for raw frozen chicken and cuts is the northeast region. So products from the main companies have to travel a considerable way by truck to be consumed.

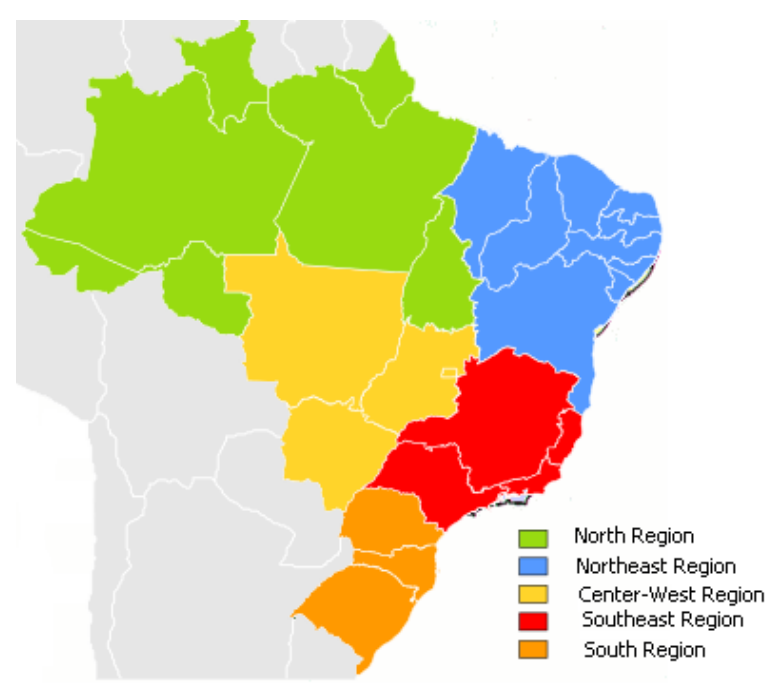

Figure 3. Regions of Brazil

Source: Wikipedia (2013).

Big companies, for around 40 years exploring this market developed a huge system of production, exportation and sales in Brazil. However, the basis of those is frozen food with few offerings of chilled meat. The frozen chicken chain starts with hen's egg being imported from USA or Canada for being the "grandmother". Those grandmothers, from when they are 20 weeks old, produce eggs for 60 weeks. Their "puppies" follow the same process and at 20 weeks, with artificially insemination of fowl sperm, will produce eggs for 60 weeks.

Those eggs will stay for around 21 days in an incubation plant in general close to breeding farms. After creation, those fowls will finally be hatching and will be transported to a farm of growing and fattening. The rearing process will take around 36 to 42 days. Then those birds will be slaughtered and their meat will pass through the so called primary processing (carcass production). Most part of the plants are equipped to generate further processing, having as final product cuts of chicken such as feet, breast, leg quarters, leg boneless, wings and so on, all of them frozen. 


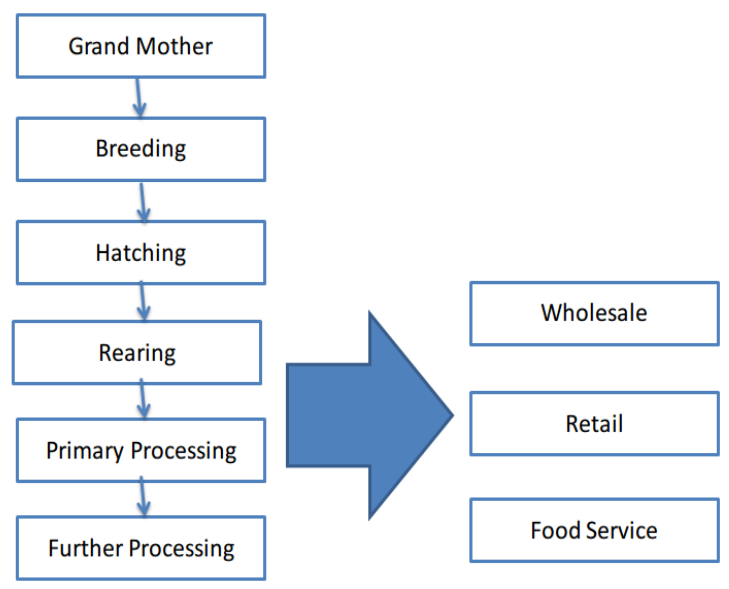

Figure 4. The flow of chicken production

Source: Case Study (2013).

The process in Brazil is not in synchrony and frozen stocks are very common. Those products are, in general, conducted until a consolidator and then they go to a regional distribution center, following the demand forecast and consensus meeting, a meeting with marketing, sales and operation of each big company, varying a little from each other, but that determines where to sell what was produced (specially the compulsory push sales one) and what to produce in pull demand plan. Most of the chicken parts are compulsorily produced because Brazil produces, for example, breast to export to Europe, and boneless leg to Japan and need to force sales of other parts of chicken in Brazil. Besides that, the frozen structures allow more time of stocks.

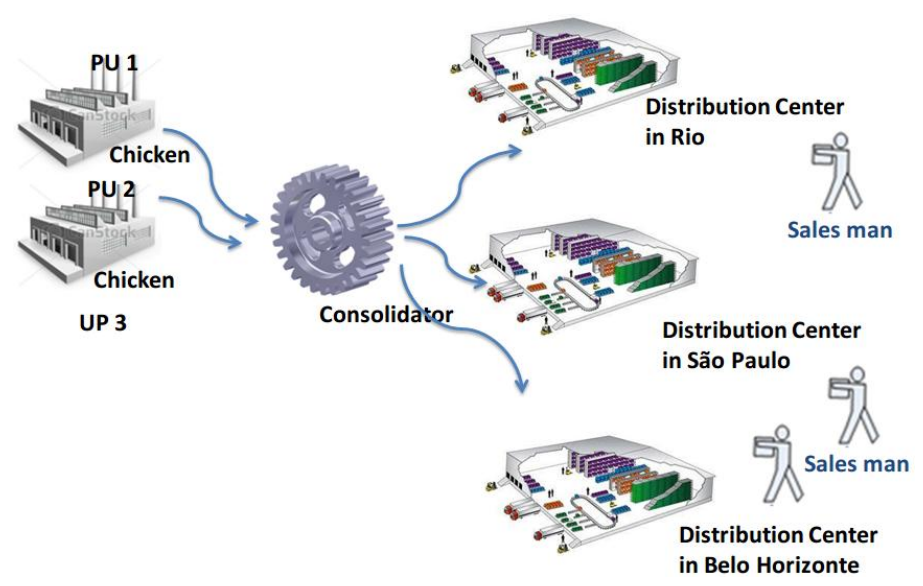

Figure 5. Distribution flow

Source: Case Study (2013).

The most important in this process is that sales force will sell only what is positioned into regional distribution centers and for chicken the most part of production is "Fordism" or a "Lean manufacturing" that pushes products into distribution systems with compulsory production. The frozen system is not working well, but it is enough to give a positive financial result for food distribution with food between from six months to two years of shelf life. The software of optimization of logistics of distribution is considering only minimum costs as objective function and it is affecting the possibility of enjoying new strategies. Production by order is something difficult to practice when there are those compulsory sales mentioned above.

An example of short shelf life food distribution is fresh milk. Below it is illustrated how fresh milk is produced in a city of Paraná, South Brazil and transported to São Paulo city, the main market where a contractor seller will pick up the shipment at a transshipment point, using small trucks and distribute it selling through bakery houses around the São Paulo metropolitan area. For the company studied the product is first sold and then it is produced 
in a make to order system. For the contractor seller, that buys productS from the industry, the sales will be simultaneously with the distribution because the product has a really small shelf life, of only 7 days.

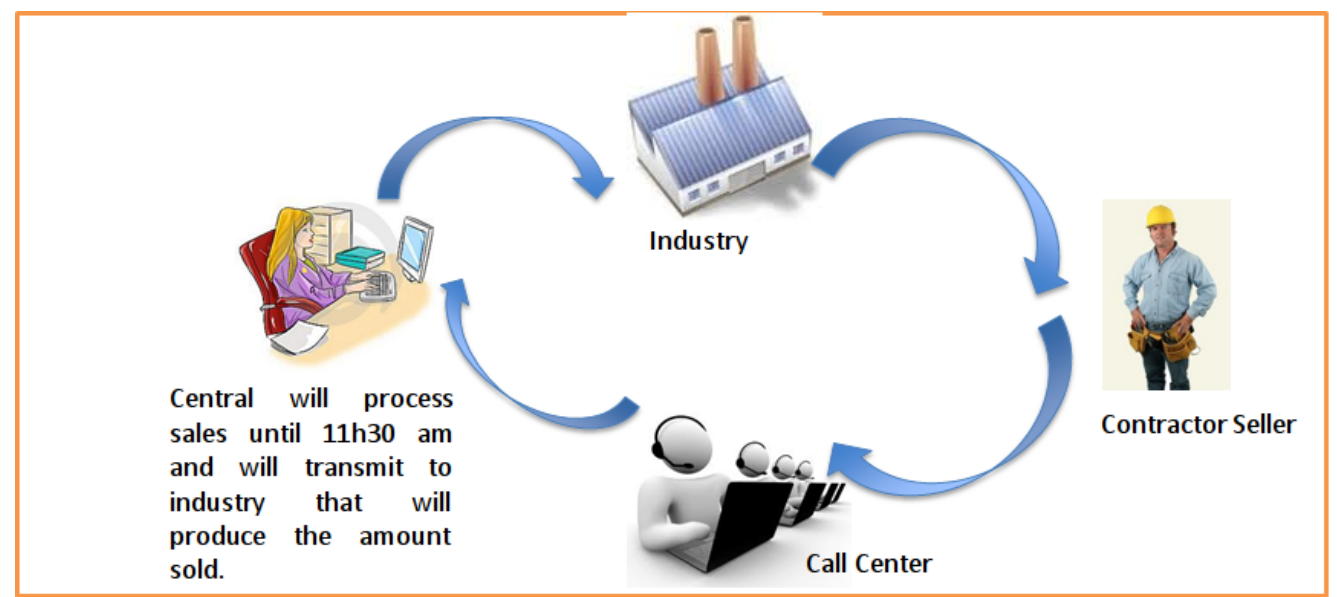

Figure 6. Fresh milk sales cycle

Source: Case Study (2013).

The milk sales cycle starts with the contractor sellers calling the call center and ordering how many liters he will need for doing his clients routes. The process will be transmitted to a central that will process and consolidate the order until $11 \mathrm{~h} 30$ am and then will transfer this order to the industry that will produce only what was ordered. The next figure shows the flow of distribution. It will be produced in Paraná, then fresh milk will pass through a transshipment and will be sold by a contractor seller to bakeries.

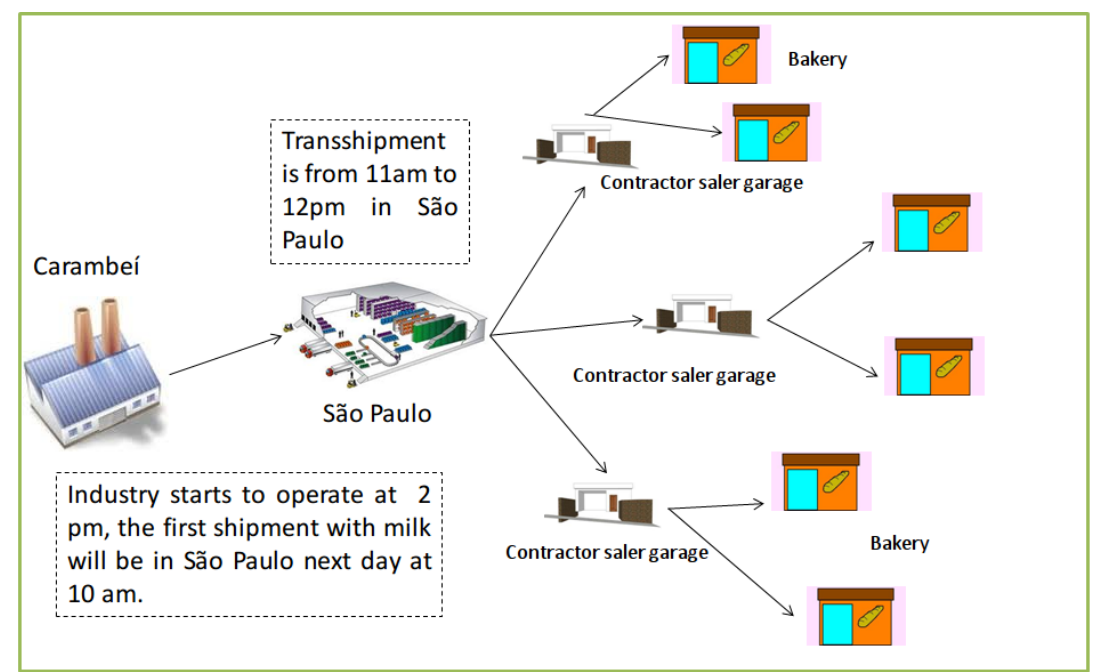

Figure 7. Fresh milk distribution

Source: Case Study (2013).

\subsection{Methodology}

The article was created from a bibliographic review of cold chain distribution and warehousing, leagile techniques and Brazilian chicken market. What was researched were models that could be given as examples to improve decisions of Brazilian company executives of how to deliver and sell cold chicken. This company is one of the main exporters of chicken in the world. After a rigorous article selection, it generated a presentation that was made to executives of that company about leagile techniques. They, then, conceived investigating the 
possibility of introducing such services.

The second part of the study was a big investigation whether it was possible and viable to implement those industrial changes. The research used a real industry as an example, collated all the struggle points and tried to find a way for making it possible to produce and delivery in postponement. As delimitation, this study has not done further simulations and it still needs some more specific practical investigation. The result, perhaps, reduced the path between theory and practice to the executives involved and, more importantle, it fulfilled the objective of coming up with a viable solution.

\subsection{Results: The Proposed New Supply Chain for Chilled Chicken}

The cuts of chilled chicken have only 10 days of shelf life, but the whole chilled carcass with no giblets has 30 days. The idea, for being viable to produce and to sell chilled chicken, is to do the further process and transport the whole carcass or the cuts only when the whole chicken, breast, wings, feet and legs are ordered. The historical week demand will define the quantity of chicken that will be transformed into chilled chicken in the next demand and their carcass will be transferred to advanced centers of processing meat according to the client's orders.

Most clients in Brazil do not buy food with more than $33 \%$ of shelf advanced. It means that the whole chilled chicken must be sold and delivered until remaining 20 days of a shelf equal to 30 days. Once cut the time to be delivered to clients is 3 days. It means that the whole process must be well synchronized with order from clients and the lead time must be short. The model Leagile is the model proposed to guarantee the chicken production and commercialization.

Primary processes will continue to be compulsory, but a part of the carcass will be raw material for chilled chicken, being stored in an atmosphere modified place waiting for orders from commercial teams to produce the final cuts and deliver with less than 3 days. It is not enough to produce final cuts in a compulsory way because their shelf is short and the waste will be considerable. Commercial teams will do their route offering, between other products, chilled chicken, with the order processed through a system and initiating final differentiation (further process) after that. Between primary and further processing there will be a stock point characterizing the decoupling point and the postponement of further processing until order is known.

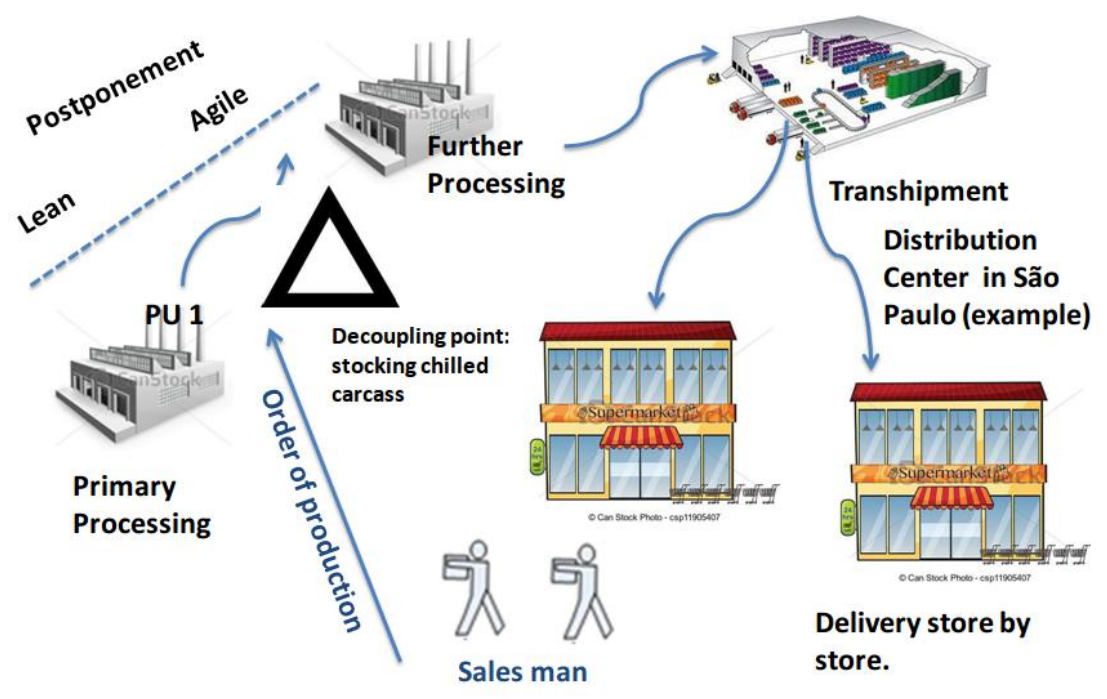

Figure 8. Leagile distribution

Source: Case Study (2013).

As the figure shows, a sales man who has a route with specific clients in his portfolio every week will have a goal to sell refrigerated food during that week. The animals that will be slaughtered will follow these initial goals; however, whole chickens will then be stored into a chamber of modified atmosphere waiting for the day before sales to be further processed. In case of the advance shelf, the whole chicken will be frozen if the legislation accepts that and will be sold as frozen food, minimizing wastes.

Those cold foods further processed will be transferred to distribution centers or transshipment points for, through 
cross docking, be delivered in a limited time of three days from further processing to clients shelf, remaining in average four days to be sold. During the entire process it is intended to develop RFID technologies for monitoring temperature during the entire product cycle.

\subsection{Correlating Theory to Proposed Study}

A whole refrigerated chicken has 30 days of shelf according to Entrup (2005) if stored in a modified atmosphere. Cuts of chicken, as said before, have 7 days. The process from chicken raising and fattening to slaughtering is a make to stock process based on forecasting and planning. The process after stocking whole chickens is a make to order strategy based on real sales order. Between those two processes, it was introduced a stock point which was called earlier decoupling point.

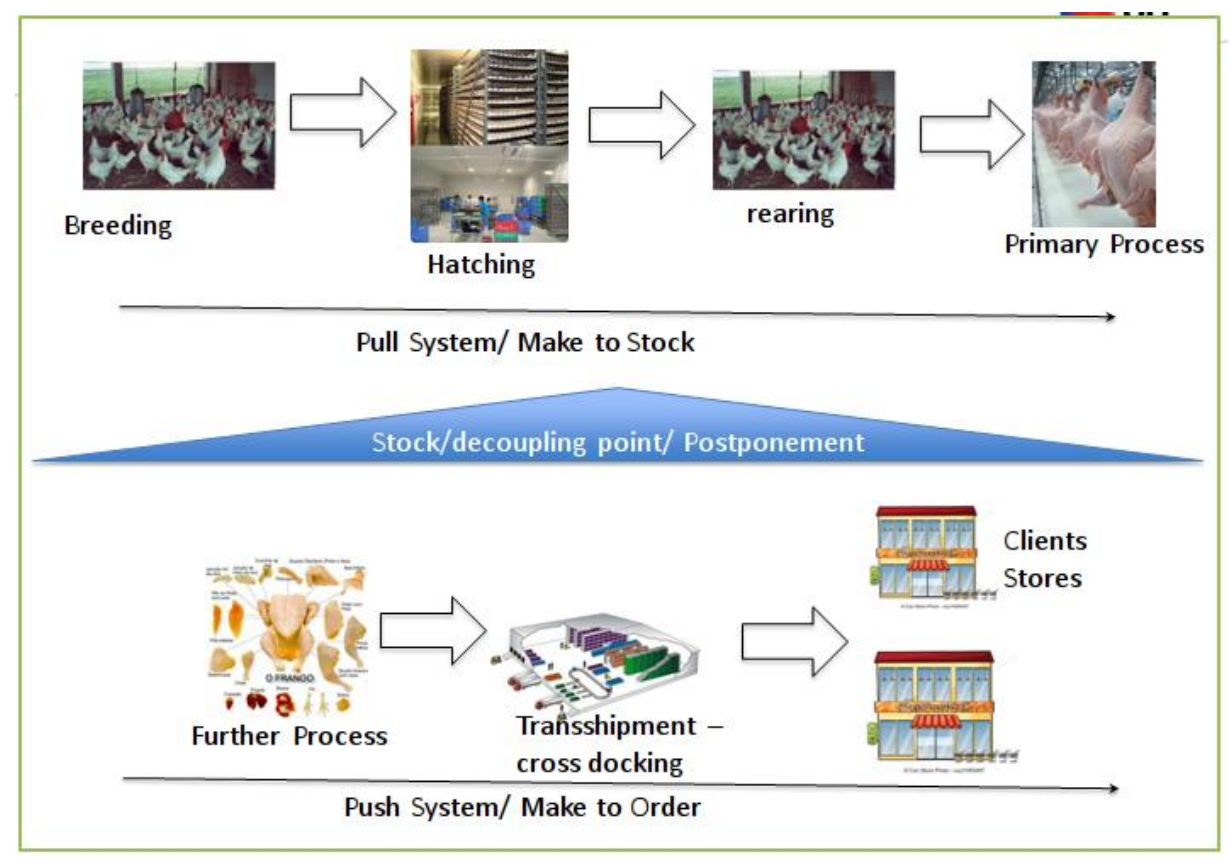

Figure 9. Therory and practices

Source: Case Study (2013).

\section{Conclusion}

It can be affirmed that this case study is possible to be implemented. However, there are lots of challenges to be overtaken. At first, the company studied has a low control of temperature and real time strategies for saving deterioration of products due to the decrease of temperature. Another point will be to prepare all production lines and put a stock point between first and further processing in factories. Nowadays it is a company's politics to not allow any stock in industries.

Another important point is that transshipment with cross docking is currently done by the company, but only from distribution centers to cross-docking points. It will be a challenge to do that departing from an industry to clients, even more because this industry can be far away from the main market. Cross-docking facilities, without passing through consolidators and distribution centers can be easily overwhelming or get low level of services. The agility necessary for that is something that will need to be developed.

It is a good resourse to have decoupling points and postponement in the food industry, once that they can give you less waste and can maximize shelf life conservation.

\section{References}

Alessandro, B., \& Marta, Z. (2009). Evaluation of product customization strategies through modularization and postponement. International Journal of Production Economics, 120(1), 205-220. http://dx.doi.org/10.1016/j.ijpe.2008.07.020

Biao, Y., Neil, D. B., \& Chris, J. B. (2004). Postponement: a review and an integrated framework. International 
Journal of Operations \& Production Management, $\quad 24(5), \quad 468-487$. http://dx.doi.org/10.1108/01443570410532542

Da-Wen, S. (2006). Handbook of Frozen Processing and Packaging. Taylor \& Francis, 1, $227-242$.

Dirk Pieter, v. D. (2001). Make to stock or make to order: The decoupling point in the food processing industries. International Journal of Production Economics, $297-306$. http://dx.doi.org/10.1016/S0925-5273(00)00035-9

Dong, T. (2011). Managing finished-goods inventory under capacitated delayed differentiation. Omega, 39(5), 481-492. http://dx.doi.org/10.1016/j.omega.2010.10.006

Gregory, A. G. (2010). A partial-postponement decision cost model. European Journal of Operational Research, 201(1), 34-44. http://dx.doi.org/10.1016/j.ejor.2009.03.001

Hartanto, W., Andrew, P., \& Mohamed, N. (2011). Evaluation of postponement in the soluble coffee supply chain: A case study. International Journal of Production Economics, 131(1), 355-364. http://dx.doi.org/10.1016/j.ijpe.2010.08.015

Hedenstierna, P., \& Ng, A. H. C. (2010). On the placement of the customer order decoupling point. Supply Chain Management and Information Systems (SCMIS), 2010 8th International Conference. Retrieved from http://ieeexplore.ieee.org/xpl/login.jsp?tp=\&arnumber=5681729\&url=http\%3A\%2F\%2Fieexplore.iee.org $\% 2$ Fxpls\%2Fabs_all.jsp\%3Farnumber\%3D5681729

James, S. (1996). The Chill Chain "from Carcass to Consumer. Meat for the Consumer 42nd International Congress of MEAT Science and Technology, 43(1), $203-216$. http://www.ncbi.nlm.nih.gov/pubmed/22060652

Jan, O. (2010). The role of the customer order decoupling point in production and supply chain management. Computers in Industry, 61(9), 863-868. http://dx.doi.org/10.1016/j.compind.2010.07.011

John, G. (1998). Strategic Supply Chain Alignment: Best practice in supply chain management. GOWER, Hampshire, England.

Marc, R. (2012). Accurate response by postponement. European Journal of Operational Research, 220(3), 619-628. http://dx.doi.org/10.1016/j.ejor.2012.02.022

Martin, C. (2005). Logistics \& Supply Chain Management. KING'S LYNN, London, Great Britain.

Matias, L. E. (2005). Advanced Planning in Fresh Food Industries. Physica-Verlag - Contributions to Management Science, 1, 1-242.

Remko, I. v. Hoek. (1999). Postponement and the reconfiguration challenge for food supply chains. Supply Chain Management: An International Journal, 4(1), 18-34. http://dx.doi.org/10.1108/13598549910255068

Remko, v. H. (1997). Postponed manufacturing: a case study in the food supply chain. Supply Chain Management: An International Journal, 2(2), 63-75.

Simone, Z., \& Lucio, Z. (2011). Chilled or frozen? Decision strategies for sustainable food supply chains. International Journal of Production Economics, 140, 731-736.

Sun, X. Y., Ji, P., Sun, L. Y., \& Wang, Y. L. (2008). Positioning multiple decoupling points in a supply network. International Journal of Production $\quad$ Economics, $113(2), \quad 943-956$. http://dx.doi.org/10.1016/j.ijpe.2007.11.012

Victoria, R., Itxaso, A., \& Maria, J. A. (2011). Tecnura, 15(30), 71-81.

Xin, X. (2011). An application of postponement strategy in supply chain. Natural Computation (ICNC), 2011 Seventh International Conference. Retrieved from http://ieeexplore.ieee.org/xpl/login.jsp?tp=\&arnumber=6022108\&url=http\%3A\%2F\%2Fieexplore.iee.org $\% 2$ Fxpls\%2Fabs_all.jsp\%3Farnumber\%3D6022108

Xuan-guo, X. (2007). Position of Customer Order Decoupling Point in Mass Customization. Machine Learning and Cybernetics, International Conference Retrieved from http://ieeexplore.ieee.org/xpl/login.jsp?tp=\&arnumber=4370159\&url=http\%3A\%2F\%2Fieexplore.iee.org $\% 2$ Fxpls\%2Fabs_all.jsp\%3Farnumber\%3D4370159 


\section{Copyrights}

Copyright for this article is retained by the author(s), with first publication rights granted to the journal.

This is an open-access article distributed under the terms and conditions of the Creative Commons Attribution license (http://creativecommons.org/licenses/by/3.0/). 